\title{
PROTOTYPE SISTEM KONTROL AIR SAWAH OTOMATIS BERDASARKAN LEVEL AIR BERBASIS MIKROKONTROLER ATmega 8535 PADA DESA BONTORAJA KABUPATEN BULUKUMBA
}

\author{
Adi Candra \\ Sistem Komputer Sekolah Tinggi Manajemen Informatika dan Komputer Bina Adinata \\ Bulukumba, Sulawesi Selatan \\ Email: chandrakirana862@gmail.com
}

\begin{abstract}
Abstrak
Prototype sistem kontrol air sawah otomatis berdasarkan level air berbasis mikrokontroler atmega8535 pada desa bontoraja kabupaten Bulukumba, Prototype ini dibuat untuk mengontrol pemberian air pada sawah sehingga para petani tidak lagi mengalami kesulitan dalam mengatur air sawahnya. Melalui pengumpulan data dan studi pustaka alat ini dirancang menggunakan sistem kontrol otomatis berdasarkan ketinggian air sawah. Prototype sistem kontrol air sawah Otomatis Berdasarkan level air berbasis Miktrokontroler ini dilengkapi dengan sensor level air yang berfungsi sebagai input dan tombol switch untuk peninjaun data ketinggian air. Mikrokontroler yang digunakan adalah ATmega8535 yang berfungsi sebagai media pemproses berdasarkan input yang masuk dan mengontrol output. Perangkat lunak yang digunakan untuk mengoperasikan mikrokontroler adalah bahasa BASIC COMPAILER. Sistem Output dari sistem ini adalah berupa motor AC. Putaran motor AC digunakan untuk mengalirkan air masuk dan keluar dari sawah.
\end{abstract}

Kata Kunci : Sawah, Pengairan Otomatis, Sensor Level air

\subsection{Latar Belakang}

\section{PENDAHULUAN}

Pengairan irigasi pertanian merupakan upaya yang dilakukan petani untuk menjaga konsistensi ketersediaan air pada lahan pertanian. Namun pemakaian air terutama pada musim kemarau tidak dapat diatur dengan baik sehingga penggunaan air sawah sering tidak sesuai dengan kebutuhan. Pengaturan air dibuat dengan tujuan dapat mencukupi kebutuhan air secara merata disetiap lahan (Najla Anwar Fuadi, 2016).

Pada sistem pengairan ini, dipergunakan pipa air varalon yang berukuran 3 inc . Pipa air ini dipasang pada mesin air yang dihubungkan langsung ke irigasi begitu juga dengan pipa pembuangan. Pipa ini digunakan untuk mengalirkan air irigasi secara merata ke dalam lahan sawah. Adapun cara pembagian air irigasi pada lahan sawah yaitu dengan memasang sejumlah sensor pada lahan yang dapat mendeteksi kondisi tanah sesuai dengan kebutuhan airnya. Untuk terwujudnya semua rancangan sistem tersebut maka dibuatlah sebuah metode algoritma prototype sistem pengontrolan air sawah secara otomatis berdasarkan level air menggunakan mikrokontroler.

1.2 Rumusan Masalah

1. Bagaimana merancangan Prototype Sistem Kontrol air sawah otomatis berdasarkan level air menggunakan Mikreokontroler.

2. Bagaimana mengimplementasikan prototype Sistem Kontrol air sawah otomatis berdasarkan level air menggunakan Mikreokontroler.

1.3 Tujuan Penelitian

1. Untuk merancang prototype Sistem Kontrol air sawah otomatis berdasarkan level air menggunakan Mikreokontroler.

2. Untuk mengimplementasikan prototype Sistem Kontrol air sawah otomatis berdasarkan level air menggunakan Mikreokontroler 


\subsection{Batasan Masalah}

Adapun batasan masalah pada sistem kontrol air sawah berdasarkan ketinggian level air yaitu dengan

1. Mengalirkan air dari level batas terendah $<=1 \mathrm{~cm}$, level sedang 10 $\mathrm{cm}$ dan batas tertinggi $15 \mathrm{~cm}$ dengan luas petak sawah $5 \times 10$ meter persegi.

2. Menggunakan Mikrokontroler ATmega8535 sebagai pemroses pengolahan data.

3. Menggunakan sensor level air jenis magnetic sebagai pemberi input ke dalam mikrokontroler

4. Menggunakan 2 Batang pipa varalon 3 inc untuk mengalirkan air sawah

5. Menggunakan bahasa Basic Kompailer sebagai bahasa pemrograman

6. Menggunakan algoritma greedy untuk menentukan titik terendah dapat berfungsi dengan baik untuk menentukan titik terdekat pada sistem pendeteksian level air.

7. Menggunakan 2 motor DC untuk memompa air ke dalam dan keluar area sawah

1.5 Manfaat Penelitian

Dapat digunakan sebagai alat untuk meningkatkan hasil pertanian dan pengaturan pengairan sawah secara otomatis berdasarkan ketinggian level air pada lahan sawah dan menjadi tolak ukur dalam mengembangkan penelitian berikutnya atau dimasa akan datang.

\section{LANDASAN TEORI}

\subsection{Perancangan}

Perancangan adalah tahapan dimana dimulai mengenai bentuk input sistem, rancangan database, output sistem dan skema alur kerja program. Langkah awal dalam perancangan desain bermula dari hal-hal yang tidak teratur berupa gagasan atau ide-ide kemudian melalui proses penggarapan dan pengelolaan akan menghasilkan hal-hal yang teratur, sehingga hal-hal yang sudah teratur bisa memenuhi fungsi dan kegunaan secara baik (Nasution 2012).

\subsection{Pengairan Sawah}

Irigasi merupakan upaya yang dilakukan manusia untuk mengairi lahan sawah pertanian. Adapun jenis-jenis irigasi yaitu sebagai berikut:

1. Irigasi Permukaan adalah pengaliran air di atas permukaan dengan ketinggian air sekitar 10-15 cm di atas permukaan tanah. Irigasi permukaan merupakan sistem irigasi yang menyadap air langsung di sungai melalui bangunan bendung maupun melalui bangunan pengambilan bebas (free intake) kemudian air irigasi dialirkan secara gravitasi melalui saluran sampai ke lahan pertanian. Di sini dikenal saluran primer, sekunder, dan tersier. Pengaturan air ini dilakukan dengan pintu air. Prosesnya adalah gravitasi, tanah yang tinggi akan mendapat air lebih dulu.

2. Irigasi Lokal adalah ini air distribusikan dengan cara pipanisasi. Di sini juga berlaku gravitasi, di mana lahan yang tinggi mendapat air lebih dahulu. Namun air yang disebar hanya terbatas sekali atau secara lokal.

3. Irigasi dengan Penyemprotan. adalah irigasi yang biasanya Penyemprotan dipakai penyemprot air atau sprinkle. Air yang disemprot akan seperti kabut, sehingga tanaman mendapat air dari atas, daun akan basah lebih dahulu, kemudian menetes ke akar.

4. Irigasi Tradisional dengan Ember. Di sini diperlukan tenaga kerja secara perorangan yang banyak sekali. Di samping itu juga pemborosan tenaga kerja yang harus menenteng ember.

5. Irigasi Pompa Air Air diambil dari sumur dalam dan dinaikkan melalui pompa air, kemudian dialirkan dengan berbagai cara, misalnya dengan pipa atau saluran. Pada musim kemarau irigasi ini dapat terus mengairi sawah.

6. Irigasi Tanah Kering dengan Terasisasi Di Afrika yang kering dipakai sistem ini, terasisasi dipakai untuk distribusi air. Ada beberapa sistem irigasi untuk tanah kering, yaitu: irigasi tetes (drip irrigation), irigasi curah (sprinkler irrigation), irigasi saluran terbuka (open ditch irrigation), dan irigasi bawah permukaan (subsurface irrigation) (Yolly Adriati 2014). 


\subsection{Sistem Pengairan}

Konsep pengairan merupakan suatu cara pengairan pada sawah yang hanya memberi air irigasi sesuai dengan jumlah dan waktu yang dibutuhkan oleh tanaman. Pengairan yang dilakukan petani padi sawah, dengan menerapkan prinsip intensifikasi yang bersifat efektif, efisien, alamiah dan ramah lingkungan. Sistem pemberian air dilakukan hampir sepanjang masa tanam, yaitu 3 bulan sebelum padi tersebut menguning. Pemberian air dilakukan dengan cara menggenangi sawah dengan ketinggian tertentu antara $1 \mathrm{~cm}$ sampai dengan $15 \mathrm{~cm}$. hal ini terus dilakukan sampai padi hampir menguning atau butir padi sudah terisi (Suria Darma Tarigan 2016).

\subsection{Sistem Kontrol}

Sistem yang digunakan pada perancangan Prototype Sistem Kontrol Air Sawah Otomatis Berdasarkan Level Air Menggunakan Mikrokontroler adalah Sistem Kontrol Otomatik. Sistem Kontrol Otomatik adalah pengontrolan yang dilakukan oleh peralatan yang bekerja secara otomatis dan operasinya dibawah pengawasan manusia. Pada sistem kontrol terbagi menjadi dua yaitu sistem kontrol kalang terbuka dan sistem kontrol kalang tertutup. Pada penelitian ini akan digunakan sistem kontrol kalang tertutup untuk mengendalikan sistem yang ada pada pengontrolan. (Katsuhiko Ogata, 1997).

\subsection{Mikrokontroler}

Mikrokontroler adalah sebuah sistem microprosesor dimana di dalamnya sudah terdapat CPU, ROM, RAM, I/O, Clock dan peralatan internal lainnya yang sudah saling terhubung dan terorganisasi (teralamati) dengan baik oleh pabrik pembuatnya dan dikemas dalam satu chip yang siap pakai. Sehingga kita tinggal memprogram isi ROM suatu aturan penggunaan oleh pabrik yang membuatnnya (Ardi Winoto, 2010).

Mikrokontroler merupakan sebuah sistem computer yang seluruh atau sebagian besar elemennya dikemas dalam satu chip IC, sehingga sering disebut Single Chip Microcomputer. Mikorokontroler mempunyai perbedan yang cukup penting dengn mikroprosesor. Mikroprosesor merupakan bagian dari CPU (Central Prosessing Unit) tampa memori dan $\mathrm{I} / \mathrm{O}$ pendukung dari sebuah computer, sedangkan mikrokontroler umumnya terdiri dari CPU, memori, I/O tertentu.

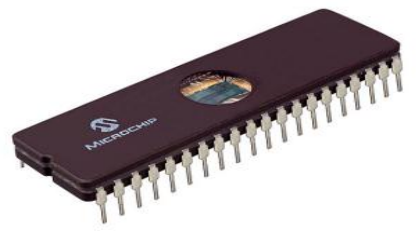

\section{Gambar 1. IC Mikrokontroler}

\subsection{Sensor Level Air}

Sensor merupakan jenis transducer yang digunakan untuk mengubah variasi mekanis, magnetis, panas, sinar dan kimia menjadi tegangan / arus listrik. Namun terdapat perbedaan antara sensor dan tranducer yaitu sensor masih membutuhkan komponen lain untuk mengeluarkan sinyal tegangan tetapi transducer tidak membutuhkan komponen yang lain untuk mengeluarkan sinyal tersebut, adapun sinyal yang dihasilkan adalah berupa sinyal elektronik.

Adapun sensor yang akan digunakan pada perancangan prototype Sistem Kontrol air sawah otomatis berdasarkan level air menggunakan Mikrokontroler adalah Sensor level air. Sensor Level air merupakan sensor yang dapat mendeteksi ketinggian air dengan cara membaca resistansi yang dihasilkan oleh air yang mengenai lempengan yang bergarisgaris pada sensor tersebut, semakin banyak air yang mengenai permukaan tersebut maka hambatannya semakin kecil dan ketika tidak ada air yang mengenai lempengan sensor tersebut maka hambatannya sangat besar atau biasa dikatakan tidak terhingga (Muhammad Rosyid Alfatah 2016).

Sensor level air dapat memberikan keluaran berupa resistansi sinyal analog yang dapat diterima dan diolah oleh perangkat Mikrokontroler. Gelombang analog inilah yang kemudian akan menghasilkan input ke dalam ping mikrokontroler, ping terdiri dari sebuah chip pembangkit sinyal.

Berikut adalah gambar perancangan elektronik dalam pembuatan sensor level air. 


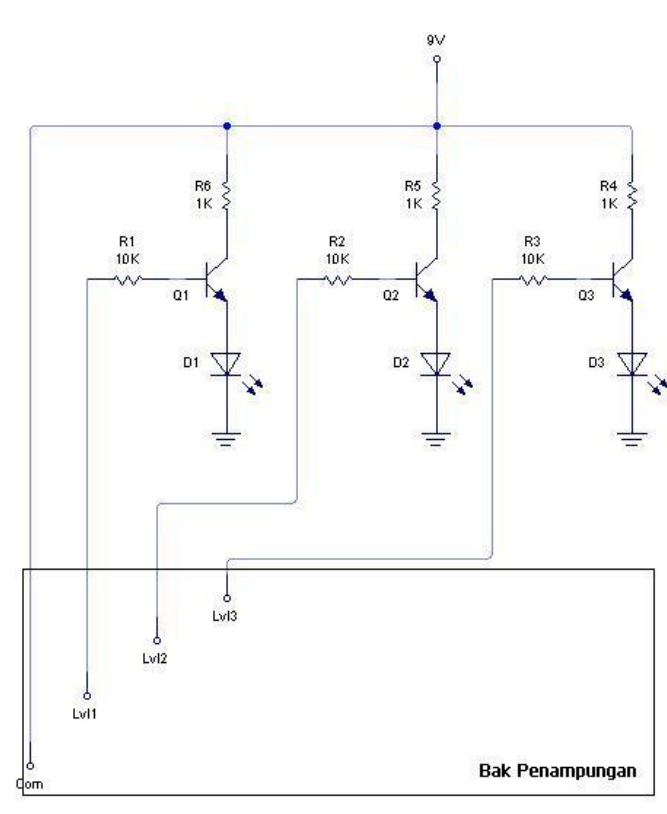

\section{METODE PENELITIAN}

\subsection{Penggambaran Sistem}

Dari hasil penelitian yang dilakukan pada lokasi perancangan sistem yang sedang berjalan adalah sebagai berikut:

1. Para petani datang kepada petugas pembagi air meminta agar di alirkan ke jalur area sawah petani.

2. Petugas mencatat dan dan menjadwal laporan dari petani kemudian memberikan jadwal kepada petani kapan air akan dialirkan.

3. Petani datang ke lokasi persawahan menunggu air sesuai jadwal yang diberikan oleh petugas pembagi air.

4. Petani menunggu di lokasi selama air mengalir ke dalam sawah hingga area sawahnya penuh

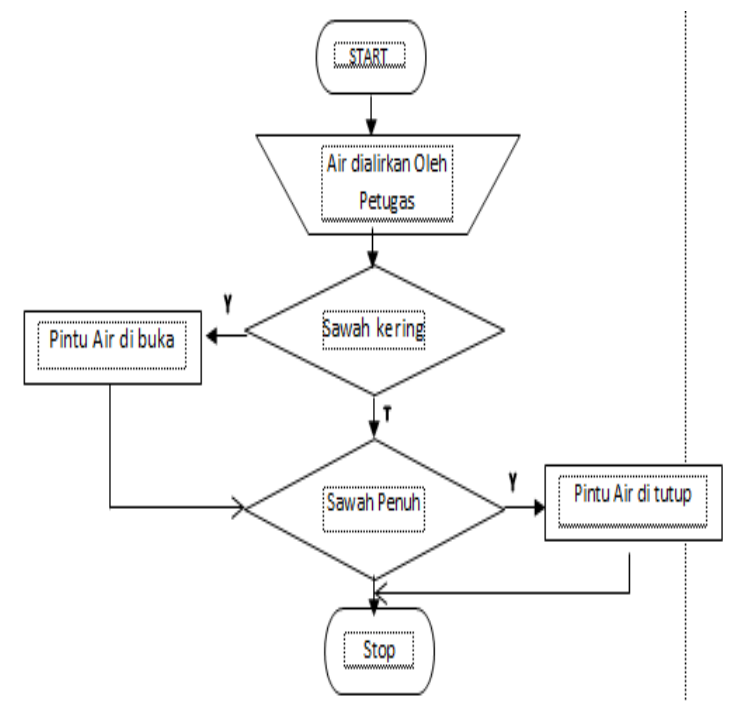

Gambar 3. Flowchart Sistem pengairan sawah secara manual

Adapun metode algoritma yang diusulkan dalam perancangan prototype sistem kontrol air sawah berdasarkan level air adalah pembuatan sistem pengontrolan air sawah secara otomatis berbasis Mikrokontroler yang digunakan untuk memudahkan dalam mengairi lahan sawah baik pada musim kemarau maupun pada musim penghujan

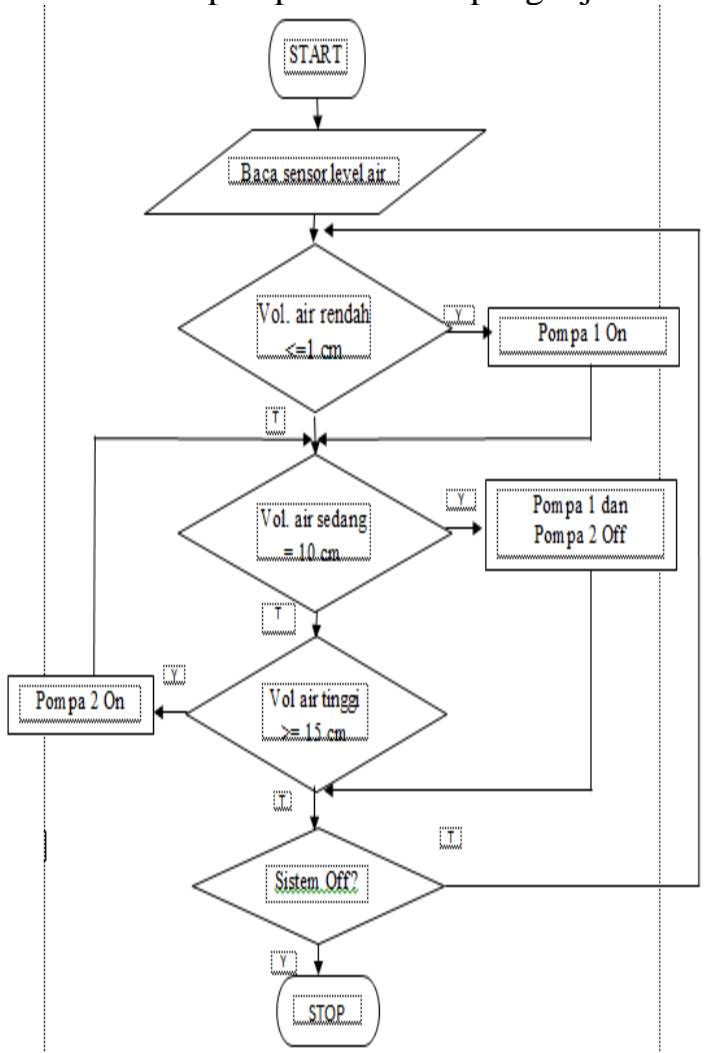


Gambar 4. Flowchart Sistem pengairan sawah berbasis Mikrokontroler

\subsection{Metode Pengembangan Sistem}

Metode yang digunakan peneliti dalam kegiatan penelitian yaitu System Development Life Cycle (SDLC) dengan metode prototype dengan teknik pengumpulan data dilaksanakan dengan tahap-tahap sebagai berikut :

a. Metode Observasi

Metode observasi yaitu metode pengumpulan data dengan cara melakukan pengamatan secara langsung proses pemasukan air sawah ke dalam area persawahan.

b. Wawancara

Wawancara yang dilakukan dengan cara tanya jawab secara langsung kepada petani yang sedang melakukan proses pemasukan air ke dalam sawahnya.

c. Pengumpulan Dokumen

1. Pengumpulan data yang dimaksud yaitu peninjauan yang dilakukan secara langsung pada objek kajian, seperti pengumpulan data yang dilakukan dengan mengadakan tanya jawab secara langsung pada pihak yang dapat memberikan informasi atau keterangan yang berkaitan dengan perancangan sistem.

2. Studi pustaka yang dimaksud yaitu suatu cara pengumpulan data dengan jalan membaca dan menelusuri literatur yang berkaitan dengan judul baik yang terdapat dalam buku-buku, majalah maupun dari media informasi seperti internet kemudian mengambil data yang diperlukan.

\subsection{Analisis Kebutuhan (SRS)}

Perangkat Lunak (Software) protototype Sistem kontrol pengairan sawah secara otomatis ini adalah dengan menggunakan bahasa BASCOM AVR. Bahasa BASCOM AVR adalah salah satu tool untuk pengembangan/pembuatan program untuk kemudian ditanamkan dan dijalankan pada microcontroller terutama microcontroller Mikrokontroler.
Untuk mengisi program ke mikrokontroler dibutuhkan alat yaitu USB ISP Downloader dan sofeware yaitu Khazama AVR Programmer, sistem input program adalah Sistem pengisian ISP, konektor yang digunakan adalah DB 9 untuk komunikasi serialnya. Untuk mengaktifkan USB ISP Downloader dibutuhkan tegangan antara 5 $12 \mathrm{~V}$.

Dalam pembuatan Prototype Sistem Kontrol air sawah otomatis ini terdiri atas beberapa komponen Rangkaian yaitu :

a. Rangkaian Mikrokontroler adalah rangkaian sistem minimum yang berfungsi sebagai pengontrol sistem I/O mikrokontroler. .

b. Rangkaian Driver Motor berfungsi untuk mengontrol putaran motor DC dimana sinyal yang keluar dari mikrokontroler merupakan sinyal digital dan akan di konversi dan diperbesar arusnya menjadi sinyal analog oleh driver motor agar motor DC dapat berputar sesuai dengan perintah mikrokontroler.

Rangkaian Power Supply yang berfungsi mengubah arus AC (bolak balik) menjadi arus DC (searah), dimana arus yang dibutuhkan oleh setiap komponen pada alat ini adalah arus DC.

\subsection{Perancangan Diagram Blok Sistem}

Perancangan ini terdapat beberapa komponen yang saling berkaitan serta saling mendukung sehingga terbentuk Prototype Sistem Kontrol Pengairan Sawah Otomatis yaitu berupa media Input, Proses dan Output. Input dari Pintu pengairan sawah ini adalah berupa sensor, diantaranya sensor Level air yang berfungsi untuk mendeteksi ketinggian air sawah.

Proses dari Pintu Irigasi sawah ini berupa ADC (Analog To Digital Converter) yang mengubah dan memperkuat sinyal analog yang masuk dari sensor ping menjadi sinyal digital sehingga dapat di proses oleh mikrokontroler. Dimana input yang masuk dari sensor akan diolah dan di eksekusi berdasarkan perintah program yang dimasukkan ke dalam mikrokontroler. Hasil dari eksekusi tersebut akan memerintahkan media output untuk bergerak sesuai dengan input sensor dan perintah mikrokontroler. 
Output dari Pintu pengairan sawah ini adalah berupa gerak rotasi pada motor DC. Arah rotasi dan kecepatan rotasi motor DC ini berdasarkan perintah input sensor dan mikrokontroler. Media yang digunakan untuk menggerakkan pintu pengairan sawah ini adalah motor DC. Adapun arsitektur sistem Prototype dari perancangan pengairan sawah secara otomatis, dapat dilihat pada gambar dibawah ini :

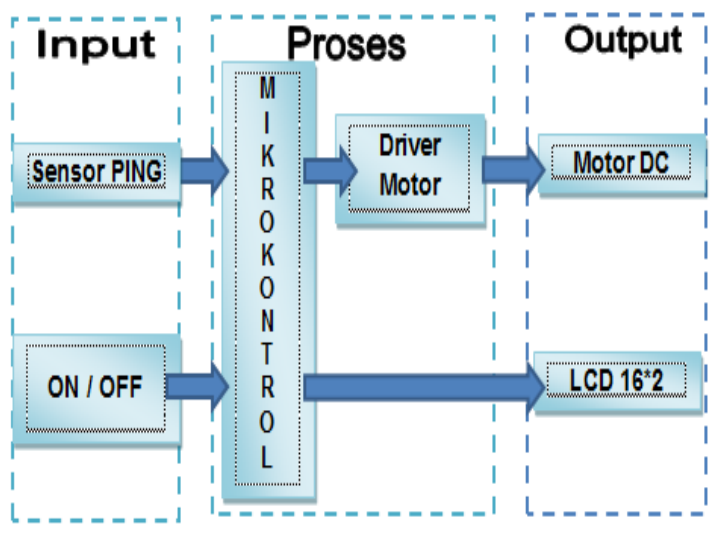

Gambar 5. Diagram Blok Rangkaian

Sistem Kontrol pengairan sawah ini terdiri atas beberapa komponen Rangkaian yaitu :

1. Rangkaian Mikrokontroler adalah rangkaian sistem minimum yang berfungsi sebagai pengontrol sistem I/O mikrokontroler. .

2. Rangkaian Driver Motor berfungsi untuk mengontrol putaran motor DC dimana sinyal yang keluar dari mikrokontroler merupakan sinyal digital dan akan dikonversi dan diperbesar arusnya menjadi sinyal analog oleh driver motor agar motor DC dapat berputar sesuai dengan perintah mikrokontroler.

3. Rangkaian Power Supply yang berfungsi mengubah arus AC (bolak balik) menjadi arus DC (searah), dimana arus yang dibutuhkan oleh setiap komponen pada alat ini adalah arus DC.

\subsection{Tahap Perancangan Sistem}

Berikut adalah tahap perancangan pembuatan Prototype sistem pengairan sawah otomatis berdasarkan ketinggian level air, antara lain :

1. Perancangan rangkaian

Adi Candra : Prototype Sistem Kontrol Air .... a. Rangkaian Sistem Minimum Mikrokontroler

Rangkaian mikrokntroler

Mikrokontroler merupakan sebagai pusat pengolahan data dari input sensor dan pengendali pada sistem actuator. Mikrokontroler yang digunakan adalah Mikrokontroler karena memiliki kemampuan yang cukup lengkap untuk aplikasi pengontrolan secara umum. Sistem minimum yang dibuat berkerja pada single chip yaitu sistem tidak ditambahkan dengan eksternal memori, baik eksternal memori program maupun eksternal memori data

b. Rangkaian Driver Motor

Rangkaian driver motor berfungsi untuk mengubah sinyal digital yang masuk dari mikrokontroler menjadi sinyal analog yang dapat dikenali oleh motor DC. Bagian inti dari driver motor ini adalah IC L298N dimana merupakan IC $H$-Bridge yang dapat mengontrol 2 motor sekaligus.

c. Rangkaian Power Supply

Power Supply adalah perangkat keras yang berfungsi untuk menyuplai tegangan langsung kekomponen yang membutuhkan tegangan listrik. Input power supply yang digunakan untuk robot berupa arus bolak-balik (AC) sehingga power supply harus mengubah tegangan AC menjadi DC (arus searah), karena komponen yang digunakan pada pintu irigasi otomatis ini hanya dapat beroperasi dengan arus DC.

2. Realisasi bentuk rangkaian dan tata letak komponen

Realisasi Gambar rangkaian yang telah dibuat kemudian diolah menggunakan komputer dan dicetak ke papan PCB dan menyusun komponen sesuai pada tempatnya. Adapun tahapan-tahapan yang dapat dilakukan adalah sebagai berikut :

a. Pengujian rangkaian pada percobaan

Pada tahap ini rangkaian yang telah dibuat akan diuji satu persatu berdasarkan dengan fungsinya masingmasing. Hal ini dilakukan agar memudahkan pada saat akan menggabungkan antara satu rangkaian 
komponen dengan komponen lainnya sehingga dapat saling terhubung dengan baik.

b. Pembuatan Printed Circuit Board (PCB) Rangkaian yang telah diuji pada papan percobaan kemudian langsung di cetak pada papan PCB sebagai berikut :

1) Mempelajari gambar rangkaian yang akan dibuat.

2) Menata letak semua komponen dengan sebaik-baiknya agar diperoleh jalur rangkaian yang pendek, rapi dan mudah jika dilakukan perbaikan atau penggantian komponen.

3) Pembuatan jalur rangkaian pada papan PCB matriks, hal ini dilakukan jika tata letak dari komponen hanya sedikit dan tidak memerlukan banyak PCB.

4) Pembuatan jalur rangkaian pada PCB dibuat sesederhana mungkin.

5) Jalur rangkaian yang dibuat tidak saling bersentuhan, serta memisahkan antara jalur input dengan output agar memudahkan pada saat pemasangannnya.

3. Pembuatan Mekanik

Dalam pembuatan pintu irigasi otomatis ini diperlukan juga perancangan mekanik agar pintu dapat terbuka dan tertutup sesuai sesuai dengan ketinggian air yang telah ditentukan. Perancangan mekanik ini berupa pengukuran panjang dan lebar tiap pintu, agar tiap pintu dapat bergerak pada porosnya dengan baik.

Diperlukan perhitungan-perhitungan dalam perancangan alat ini, karena jika salah perhitungan pada pemotongan pintu maka akan sangat berpengaruh besar pada proses buka tutup pintu irigasi itu sendiri. Bagian pintu yang membutuhkan pengukuran yaitu poros buka tutup pintu kemudian pemotongan panjang dan lebar pintu yang diukur sesuai dengan porosnya, dengan tujuan pintu dapat berfungsi dengan baik dan meminimalis air yg keluar dari sela antara pintu dengan porosnya.

4. Pembuatan Perangkat Lunak (Software)

Pembuatan dan pengisian program ke mikrokontroler dibutuhkan alat yaitu USB ISP Downloader dan sofeware yaitu Khazama AVR Programmer, sistem input program adalah Sistem pengisian ISP, konektor yang digunakan adalah DB 9 untuk komunikasi serialnya. Untuk mengaktifkan USB ISP Downloader dibutuhkan tegangan antara $5-12 \mathrm{~V}$. Berikut langkah-langkah pengisian program ke dalam mikrokontroler sebagai berikut :

a. Pasang konektor usb dari USBasp downloader ke komputer, dan konektor isp ke mikrokontroler

b. Instal driver USBasp

c. Cek dengan device manager, harus muncul USBasp

d. Install program Khazama

e. USB downloader siap digunakan

f. Buat program menggunakan codevisionAVR, kemudian compile/build dan make

g. Setelah membuat programserta mengcompile pada codeVisionAVR, maka file *.hex akan terbentuk, file itu yang akan dimasukkan ke dalam memori flash IC Mikrokontrole AVR.

h. Pilih menu file-load FLASH file to buffer kemudian cari lokasi dimana file *.hex itu berada, kemudian klik file hex dan klik open.

\section{HASIL DAN PEMBAHASAN}

4.1 Sistem Kontrol Pengairan Sawah Berbasis Mikrokontroler

Pengembangan sistem kontrol air sawah otomatis berdasarkan ketinggian level air berbasis Mikrokontroler diharapkan dapat membantu petani dalam menyelesaikan permasalahan pengairan irigasi sawah. Sistem ini dikembangkan dengan menggunakan algoritma greedy dalam hal menetukan titik level ketinggian pada irigasi sawah.

Pada penelitian ini digunakan 8 buah sensor untuk mendeteksi level ketinggian air sawah, dimana setiap sensor dapat mendeteksi level air rendah, sedang dan tinggi. Pada saat kondisi air sawah berada pada level rendah maka sensor akan memberikan input ke mikrokontroler bahwa sawah membutuhkan air irigasi, kemudian mikrokontroler akan memerintahkan pompa air untuk memasukan air ke dalam sawah.

Selama proses pengisian tersebut sensor air akan mendeteksi hingga pada level 
sedang. Jika sudah mencapai level sedang maka pompa air akan otomatis berhenti mengisi air kedalam sawah. Fungsi sensor mendeteksi level air paling tinggi adalah ketika kondisi air dalam sawah terlalu banyak atau dalam kondisi hujan maka secara otomatis sensor level tinggi akan medeteksi kemudian mikrokontroler memberikan perintah kepada pompa air untuk mengeluar air yang berada dalam sawah hingga level sedang, sehingga dalam keadaan apapun level air dalam sawah selalu stabil dan terjaga.

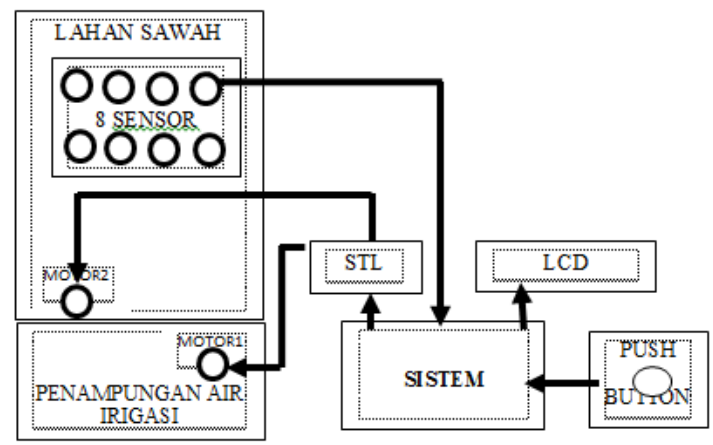

Gambar 6. Arsitektur Sistem

\section{2 Penggunaan Sensor Level air}

Pemanfaatan sensor level air ini akan sangat membantu petani dalam mengontrol sistem irigasi air sawah sehingga diharapkan akan membentu petani dalam meningkatkan hasil panen sesuai dengan yang diharapkan. Pengaturan pengairan sawah dapat dikontrol secara otomatis dengan mengatur sensor level air yang ada pada lahan sawah sesuai kebutuhan lahan, semakin banyak titik sensor yang digunakan maka semakin baik kualitas sistem pemdeteksi pada sensor level air.

Penggunaan pompa air dalam tehnik irigasi ini akan sangat membantu dibandingkan dengan cara sistem irigasi pintu karena voume air dapat dikontrol dengan cepat dan respon dari sensor serta pompa air sangat baik dalam mengontrol volume air yang ada pada sawah.

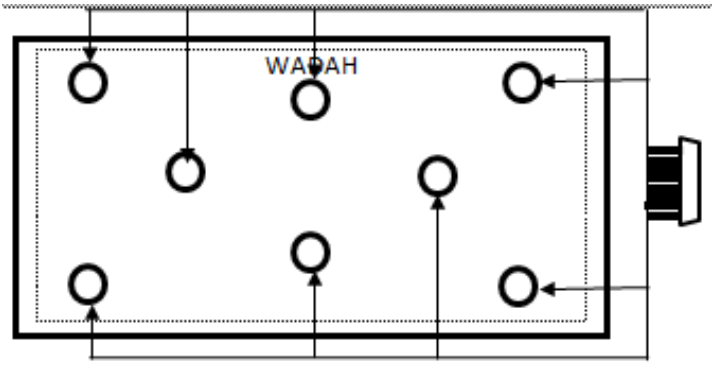

Gambar 7. Arsitektur penampang sensor Level air

\subsection{Perancangan Antar Muka}

Pada penelitian ini telah dibangun sistem pengairan sawah berdasarkan ketinggian level air berbasis Mikrokontroler. Terdapat tiga bagian sistem dalam pengontrolan ini yaitu input, proses dan output. Input dari sistem ini adalah menggunakan 8 buah sensor level air. Setiap sensor memiliki beberapa tingkatan level deteksi air yaitu rendah, sedang dan tinggi.

Pada sensor level tinggi berfungsi untuk mendeteksi jika kondisi level air terlalu banyak, karena jika air terlalu banyak juga tidak baik untuk perkembangan padi di sawah. Ketika sensor level tinggi mendeteksi air terlalu banyak maka mikrokontroler akan memerintahkan pompa air untuk menghisap air yang ada didalam sawah. Proses ini akan terus berjalan hingga sensor level sedang mendeteksi ketinggian air.

Berikut adalah gambar simulasi sawah dan sensor

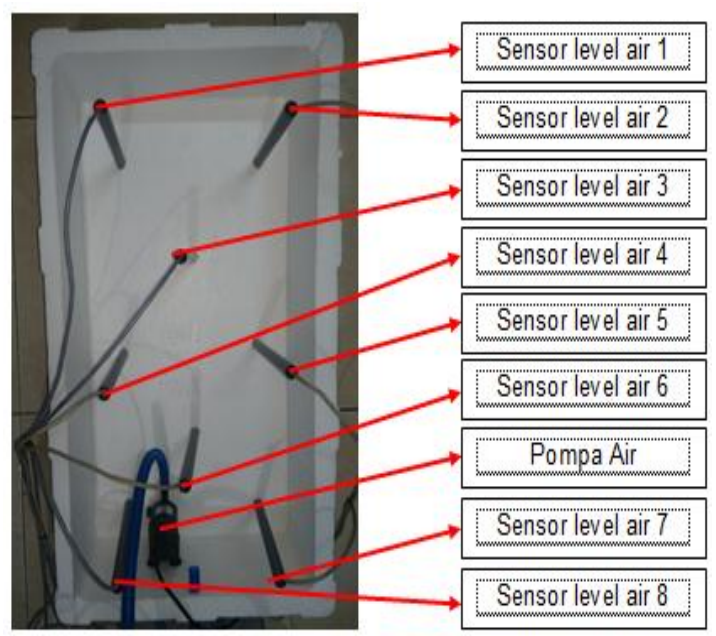

Gambar 8. Blok Diagram Sensor dan Sawah 
Proses pada sistem ini adalah menggunakan mikrokontroler ATMega 8535, mikrokontroler ini dapat bekerja dengan baik serta mempunyai banyak pin $I / O$ untuk mengontrol sistem pengairan irigasi sawah. Perangkat lunak yang digunakan untuk mengntrol sistem adalah menggunakan bahasa pemrograman Basic.

Output dari sistem ini adalah LCD 16x2 dan relay, LCD 16x2 berfungsi untuk memberikan informasi kepada pengguna sedangkan relay berfungsi untuk mengontrol on/off dari pompa air. Terdapat dua pompa air yang digunakan pada sistem ini yaitu pompa air untuk memasukkan air kedalam sawah dan pompa air untuk menghisap air keluar dari sawah. Pompa air ini dapat aktif ketika relay mendapat perintah 1 dari mikrokontroler dan akan off jika relay mendapat logika 0 dari mikrokontroler.

Berikut adalah gambar perancangan elektronika.

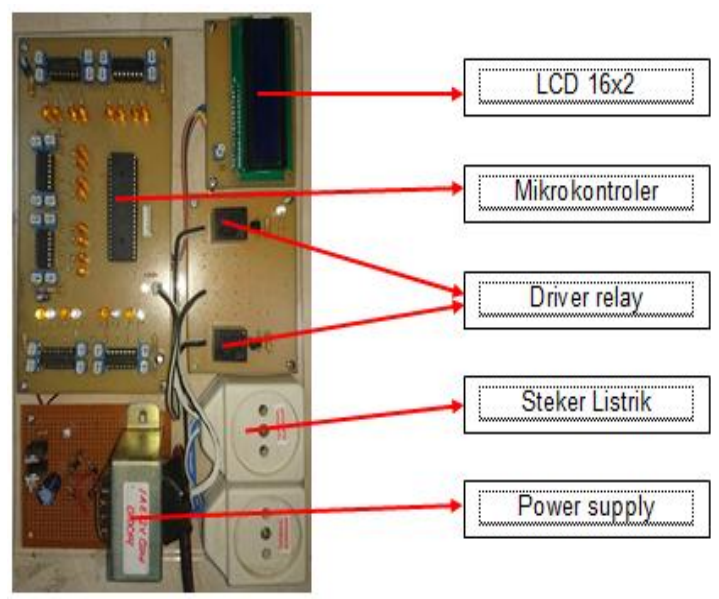

Gambar 9. Blok Diagram Sistem 1

Sistem secara keseluruhan dapat berjalan secara otomatis dan bekerja sesuai dengan peningkatan level air yang ditentukan, dimana pada sistem ini level terendah pada volume air adalah pada level rendah $1 \mathrm{~cm}$, level sedang $10 \mathrm{~cm}$ dan level tinggi $15 \mathrm{~cm}$. Konfigurasi sensor air didasarkan pada jenis tanaman padi yang ditanam di sawah, sehingga perlu ada konfigurasi terlebih dahulu dari sensor sebelum sistem ini dijalankan. Selain itu penempatan sensor juga sangat berpengaruh dimana tidak semua permukaan sawah sama antara sisi satu dengan lainnya. Berikut adalah gambara simulasi sistem yang telah dibangun.

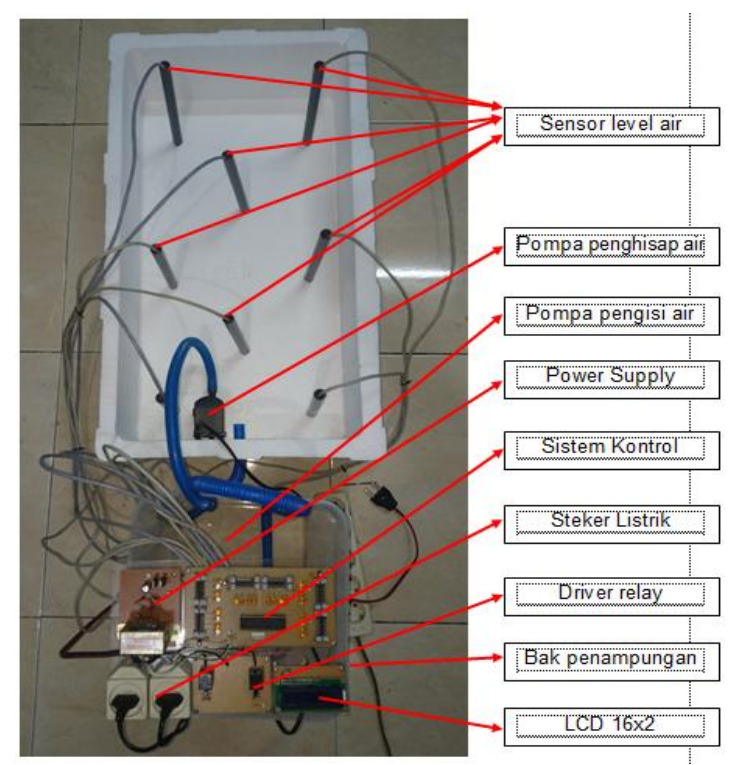

Gambar 10. Blok Diagram Sistem 2

\subsection{Implementasi}

Hasil dari penelitian ini terdapat tiga bagian sistem dalam pengontrolan yaitu input, proses dan output ditambah 8 sensor level air yang memiliki beberapa tingkatan level deteksi air yaitu rendah, sedang dan tinggi.

Sensor setiap level akan mendeteksi keberadaan air, jika sensor level rendah mendeteksi keadaan air maka sensor akan mengirimkan sinyal ke mikrokontroler untuk mengaktifkan pompa air dan menghisap air irigasi ke dalam sawah. Proses pengisian ini akan terus berjalan hingga sensor level sedang mendeteksi dan pompa akan mati. Pada sensor level tinggi berfungsi untuk mendeteksi jika kondisi level air terlalu banyak, karena jika air terlalu banyak juga tidak baik untuk perkembangan padi di sawah. Ketika sensor level tinggi mendeteksi air terlalu banyak maka mikrokontroler akan memerintahkan pompa air untuk menghisap air yang ada di dalam sawah.

Proses pada sistem ini adalah menggunakan mikrokontroler ATMega8535, mikrokontroler ini dapat bekerja dengan baik serta mempunyai banyak pin $I / O$ untuk mengontrol sistem pengairan irigasi sawah. Perangkat lunak yang digunakan untuk mengntrol sistem adalah menggunakan bahasa pemrograman Basic. 
Output dari sistem ini adalah LCD 16x2 dan relay, LCD $16 \times 2$ berfungsi untuk memberikan informasi kepada pengguna sedangkan relay berfungsi untuk mengontrol on/off dari pompa air. Terdapat dua pompa air yang digunakan pada sistem ini yaitu pompa air untuk memasukkan air kedalam sawah dan pompa air untuk menghisap air keluar dari sawah. Pompa air ini dapat aktif ketika relay mendapat perinrah 1 dari mikrokontroler dan akan off jika relay mendapat logika 0 dari mikrokontroler.

Sistem secara keseluruhan dapat berjalan secara otomatis dan bekerja sesuai dengan letingkatan level air yang di tentukan, dimana pada sistem ini level terendah pada volume air adalah pada level rendah $1 \mathrm{~cm}$, level sedang $5 \mathrm{~cm}$ dan level tinggi $10 \mathrm{~cm}$. Konfigurasi sensor air didasarkan pada jenis tanaman padi yang ditanam disawah, sehingga perlu ada konfigurasi terlebih dahulu dari sensor sebelum sistem ini dijalankan. Selain itu penempatan sensor juga sangat berpengaruh dimana tidak semua permukaan sawah sama antara sisi satu dengan lainnya.

\section{Pengujian Sistem}

Pengujian sistem pada penelitian ini adalah dengan menggunakan metode black box, yaitu pengujian yang tidak memperdulikan mekanisme internal pada sebuah sistem dan hanya berfokus pada keluaran yang dihasilkan sebagai respon dari pelaksanaan sebuah kondisi yang diinginkan pada pengujian dengan metode black box. Pada pengujian sistem penelitian ini terbagi manjadi dua bagian, yaitu pengujian perangkat keras dan pengujian perangkat lunak.

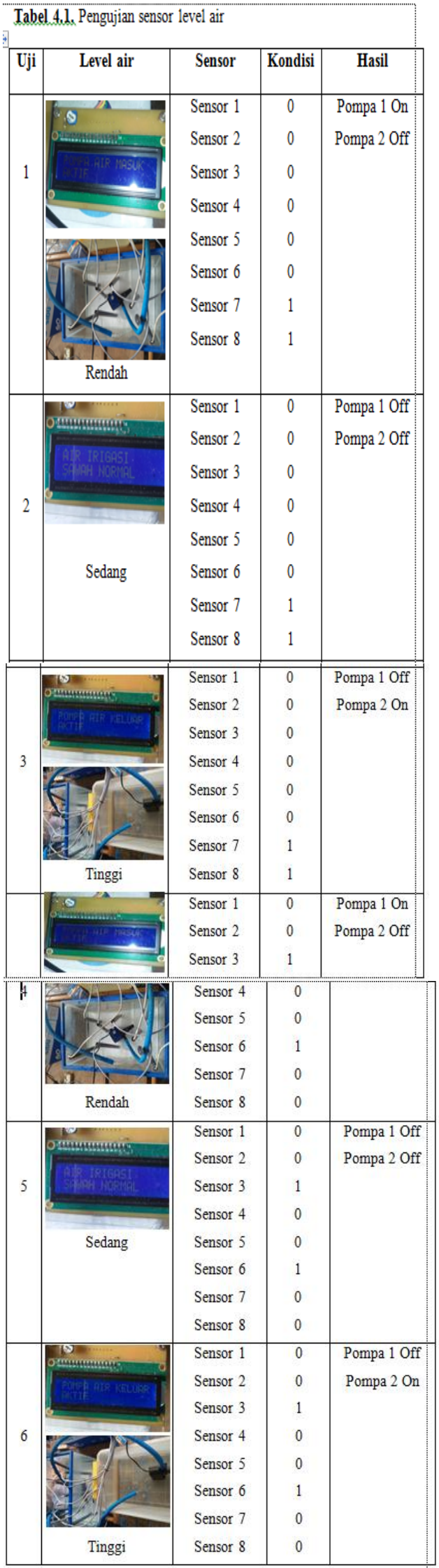


Pada pembacaan tabel 4.1 setiap sensor mempunyai level yaitu rendah, sedang dan tinggi. Ketika 2 atau lebih sensor rendah aktif maka pompa air 1 akan aktif untuk memasukkan air ke dalam sawah, jika 2 atau lebih sensor level sedang terdeteksi maka pompa air 1 dan 2 akan off dan kondisi air dalam keadaan normal. Jika 2 atau lebih sensor level tinggi aktif maka menandakan bahwa kondisi air sangat banyak dan pompa 2 akan aktif untuk mengeluarkan air yang ada di dalam sawah. Sistem yang digunakan untuk mengaktifkan pompa 1 dan pompa 2 adalah menggunakan driver relay, dimana driver relay akan aktif jika mendapatkan perintah dari mikrokontroler.

V. Kesimpulan dan Saran

\subsection{Kesimpulan}

Berdasarkan analisa dan hasil pengujian prototype sistem kontrol air sawah otomatis berdasarkan ketinggian level air berbasis arduino ini maka dapat ditarik beberapa kesimpulan yaitu:

1. Perancangan prototype sistem kontrol air sawah otomatis berdasarkan ketinggian level air berbasis arduino dapat diterapkan untuk sistem pengairan irigasi sawah.

2. Pengimplementasian prototype sistem kontrol air sawah otomatis berdasarkan ketinggian level air berbasis arduino dapat digunakan untuk meningkatkan hasil pertanian padi para petani.

3. Pemanfaatan sensor level air untuk mendeteksi ketinggian level air pada sawah sehingga dapat mendeteksi dengan baik level rendah $<=1 \mathrm{~cm}$, level sedang 10 $\mathrm{cm}$ dan level tinggi $15 \mathrm{~cm}$.

4. Pemanfatan algoritma greedy untuk menentukan titik terendah dapat berfungsi dengan baik untuk menentukan titik terdekat pada sistem pendeteksian level air dan menggunakan BASCOM sebagai bahasa pemrograman.

5. Pemanfaatan pompa air untuk mengontrol keluar masuknya air irigasi sawah sehingga dapat berfungsi dengan pola pengisian dan penghisapan air sawah.

\subsection{Saran}

Adapun saran dari hasil penelitian ini yang dapat dikembangkan adalah:
1. Sensor pembacaan level air dapat terkoneksi secara wireless tanpa menggunakan kabel.

2. Sistem dapat dikontrol menggunakan jaringan internet

3. Perlu ditambahkan sistem pembacaan sensor dan algoritma yang baik jika kondisi dataran sawah tidak sama.

\section{DAFTAR PUSTAKA}

[1] Ardi Winoto, (2010) Mikrokontroler AVR ATmega8/32/16/8535 dan Pemrogramannya dengan Bahasa $\mathrm{C}$ pada WinAVR. Bandung : Penerbit INFORMATIKA.

[2] Article,(2015). Pengertian Irigasi (on line)

http://www.galeripustaka.com/2013/03/ pengertian-dan-tujuan-irigasi.html, diakses 14 Agustus 2015

[3] Article,(2015). Arsitektur ATmega 8535 (on line) http://www.tokoelektronika.com/tutorial/uc1_fichiers/i $\begin{array}{lll}\text { mage004.jpg, } & \text { diakses } & 10\end{array}$ November2014

[4] Ainul Yaqin (2014). Pengertian Power Suply (on line). http://www.cintateknologi.com/2014/1 2/pengertian-fungsi-dan-jenis-powerSupply.html, diakses 14 Agustus 2015

[5] Azhie, (2012). Pengertian Sensor (on line).

http://www.azhie.net/2012/03/perbedaa n-sensor-dengan-tranducer.html, 10 November 2014

[6] Rahman \& Sulistiyanto (2019). Prototipe Palang Pintu Parkir Otomatis dan Informasi Parkir Kendaraan Roda Empat di Pondok Pesantren Nurul Jadid dengan Sensor Infra Red Berbasis Mikrokontroller, Jurnal JEECOM 1,1

[7] Bagus Rehan,( 2014). Konigurasi Pin LCD 16x2 (on line) http://www.bagusprehan.com/2013/12/ konfigurasi-pin-lcd-16x2.html, diakses 14 Agustus 2015

[8] Didin Wahyuddin (2012) Belajar Mudah Mikrokontroler AT89S52 dengan Bahasa Basic Menggunakan BASCOM-8051. Yogyakarta : Penerbit ANDI 
JEECOM, Vol. 2, No. 1, April 2020

[9] Dwi Pipit Haryanto dan Anto Cuswanto,

2010). Otomatis Pengisian

Penampung Air Berbasis

Mikrokontroler ATmega8535 (pdf,on

line)

http://jurnal.unimed.ac.id/2012/index.p

hp/ekodik/article/download/508/309,

diakses 10 November2014 